\title{
ARTERIAL SUPPLY OF THE HUMAN FETAL TESTIS DURING ITS MIGRATION
}

\author{
FRANCISCO J. B. SAMPAIO,* LUCIANO A. FAVORITO, MARCELO A. FREITAS, RONALDO DAMIÃO \\ AND EDUARDO GOUVEIA
}

From the Urogenital Research Unit and Division of Urology, State University of Rio de Janeiro, Rio de Janeiro, Brazil

\section{ABSTRACT}

Purpose: Irrespective of the surgical technique chosen to treat high undescended testis, preservation of an adequate arterial supply for the testis is crucial for successful orchiopexy with maintenance of normal testicular size and texture. To provide an anatomical background for such a procedure, we performed a systematic study on the number and origin of arteries supplying the fetal testis during its migration from the abdomen to the scrotum.

Materials and Methods: We studied bilaterally 64 testes from 32 fresh human fetuses 13 to 33 weeks after conception. The fetuses were injected through the thoracic aorta with a microvascular silicone rubber red resin to fill in the arterial tree, thereby enabling identification and dissection of all arteries supplying the testes.

Results: Of the 64 testes 3 arteries (testicular, deferential and cremasteric) were found in 46 (71.9\%), 2 (testicular and deferential) in $15(23.4 \%)$ and 4 in $3(4.7 \%)$.

Conclusions: The fetal testis is always supplied by at least 2 arteries (testicular and deferential arteries) and by 3 or 4 arteries in nearly $80 \%$ of the cases.

\section{KEY WoRDs: testis, arteries, fetal development, cryptorchidism, anatomy}

Cryptorchidism is the most common genitourinary disorder occurring in childhood. The number of orchiopexies has tripled in recent years and, consequently, the number of subfertile adults resulting from untreated cryptorchidism has diminished. ${ }^{1}$ High undescended testis may be present in 20 to $34 \%$ of patients with cryptorchidism. ${ }^{2,3}$ Although 40 to $50 \%$ of intra-abdominal testes can be successfully brought down into the scrotum by standard orchiopexy, surgery of the high undescended testis is challenging. ${ }^{3-6}$ When high retroperitoneal dissection does not provide adequate spermatic vessel length to allow descent without tension, special procedures are required to accomplish successful repair. In these cases many techniques have been proposed, including division of the spermatic vessels in 1 or 2 stages, ${ }^{4,7-9}$ first stage clip laparoscopic ligation of the spermatic vessels with a second stage orchiopexy 2,5,10,11 and microvascular autotransplantation of the intra-abdominal testes. ${ }^{12-14}$

Irrespective of the surgical technique, preservation of an adequate arterial supply for the testis is crucial for successful orchiopexy to ensure normal testicular size and texture. A few studies on the vascular anatomy of the testes have been performed in adults ${ }^{15-17}$ as well as in patients with abdominal cryptorchidism. ${ }^{8,12}$ However, to our knowledge there has been no systematic study of testicular arteries in human fetuses. We analyzed the number and origin of arteries supplying the fetal testis during its migration from the abdomen to the scrotum.

\section{MATERIAL AND METHODS}

We studied bilaterally 64 testes from 32 fresh human fetuses dead from causes not related to the urogenital tract. The fetuses were macroscopically well preserved and showed no signs of congenital malformation. Gestational age ranged from 13 to 33 weeks after conception and was estimated

Accepted for publication December 18, 1998.

Supported by Grant 302.369/86.4/BM-FV from the National Council of Scientific and Technological Development (CNPq-Brazil).

$*$ Requests for reprints: Caixa Postal No. 46.503, Rio de Janeiro, RJ, 20562-970, Brazil. according to the foot length method. ${ }^{18-21}$ The fetuses were evaluated with regard to foot length, crown-rump length and body weight. After classification they were injected through the thoracic aorta with a microvascular silicone rubber red resin to fill in the arterial tree. The testes were identified and their vessels were dissected under low magnification using a surgical diploscope. Since this resin was specially designed to fill every small vessel, the resulting casts enabled identification of all testicular arteries.

\section{RESULTS}

The samples included all phases of testicular migration (table 1). Table 2 shows the frequency distribution of the arteries supplying the testis. During the fetal period the epididymis and vas are intimately associated with the testis $^{21}$ and, therefore, the vasal artery is intimately associated with the epididymis. However, to facilitate visualization of the vessels we depicted the vasal arteries approaching the testis somewhat far from the epididymis.

Of the 64 testes 3 arteries (testicular, deferential and cremasteric, fig. 1) were found in $46(71.9 \%), 2$ (testicular and deferential, fig. 2) in $15(23.4 \%)$ and 4 (fig. 3) in $3(4.7 \%)$.

TABLE 1. Fetal age and testicular position

\begin{tabular}{ccc}
\hline Wks. After Conception & No. Fetuses & Testicular Position \\
\hline 13 & 1 & Abdominal \\
14 & 1 & Abdominal \\
15 & 4 & Abdominal \\
16 & 2 & Abdominal \\
17 & 1 & Abdominal \\
18 & 3 & Abdominal \\
19 & 3 & Abdominal \\
20 & 3 & Abdominal \\
21 & 3 & Abdominal \\
22 & 2 & Abdominal \\
23 & 3 & Abdominal/2 inguinal \\
24 & 1 & Abdominal \\
27 & 1 & Scrotal \\
28 & 3 & Scrotal \\
33 & 1 & Scrotal \\
\hline
\end{tabular}


TABLE 2. Arterial supply of the human fetal testis

\begin{tabular}{ccl}
\hline No. Arteries & No. Testes $(\%)$ & \multicolumn{1}{c}{ Arteries } \\
\hline 2 & $15(23.4)$ & Testicular, deferential \\
3 & $46(71.8)$ & Testicular, deferential, cremasteric \\
4 & $3(4.7)$ & Testicular, 2 deferential, cremasteric \\
\hline
\end{tabular}

Testes supplied with only 2 arteries were in the abdomen. Applying the chi-square test, we did not find a statistically significant difference in testicular vascularization between the right and left sides.

\section{DISCUSSION}

The adult testis is supplied by 3 arteries which have distinct origins and routes. According to the official nomenclature, these arteries are the testicular artery (internal spermatic artery) which originates from the abdominal aorta, the deferential artery (vasal artery) which originates in the inferior vesicle artery and the cremasteric artery (external spermatic artery) which is a branch of the inferior epigastric artery. Previous studies performed during surgical procedures and using intravascular repletion in adult cadavers showed the existence of multiple anastomotic channels among these arteries. ${ }^{8,12,15-17}$

Division of the spermatic vessels to treat a high undescended testis that cannot be brought into the scrotum by conventional techniques was first introduced as early as 1902.9 This method gained more widespread use after 1959 when Fowler and Stephens studied the vascular anatomy of the testis and described the technique in 12 patients. ${ }^{7}$ Lee et al showed that clearly visible anastomotic channels of large caliber vessels were present between the testicular and deferential arteries in $87 \%$ of specimens from adult and pediatric patients. ${ }^{15}$ Because of these anastomoses, they stated that

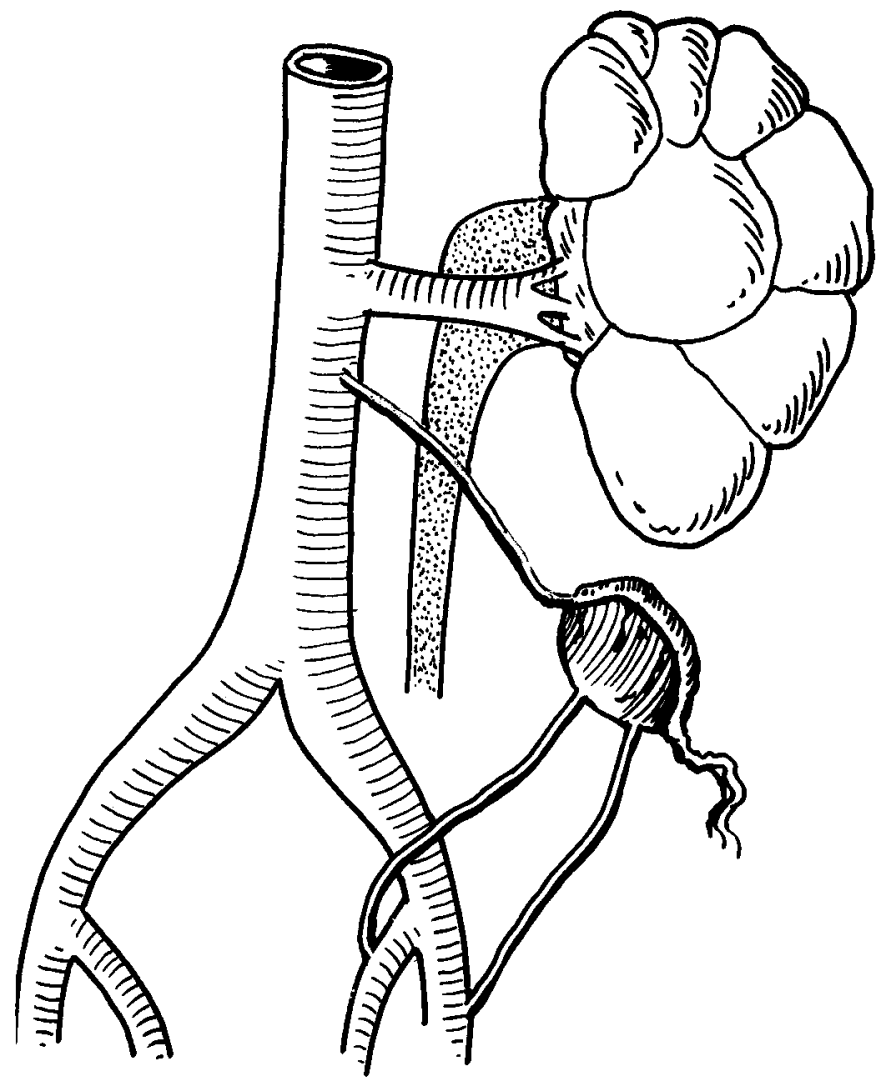

Fig. 1. Anterior view of fetal testis irrigated by 1 artery from aorta (testicular), 1 from internal iliac artery (deferential) and 1 from external iliac artery (cremasteric).

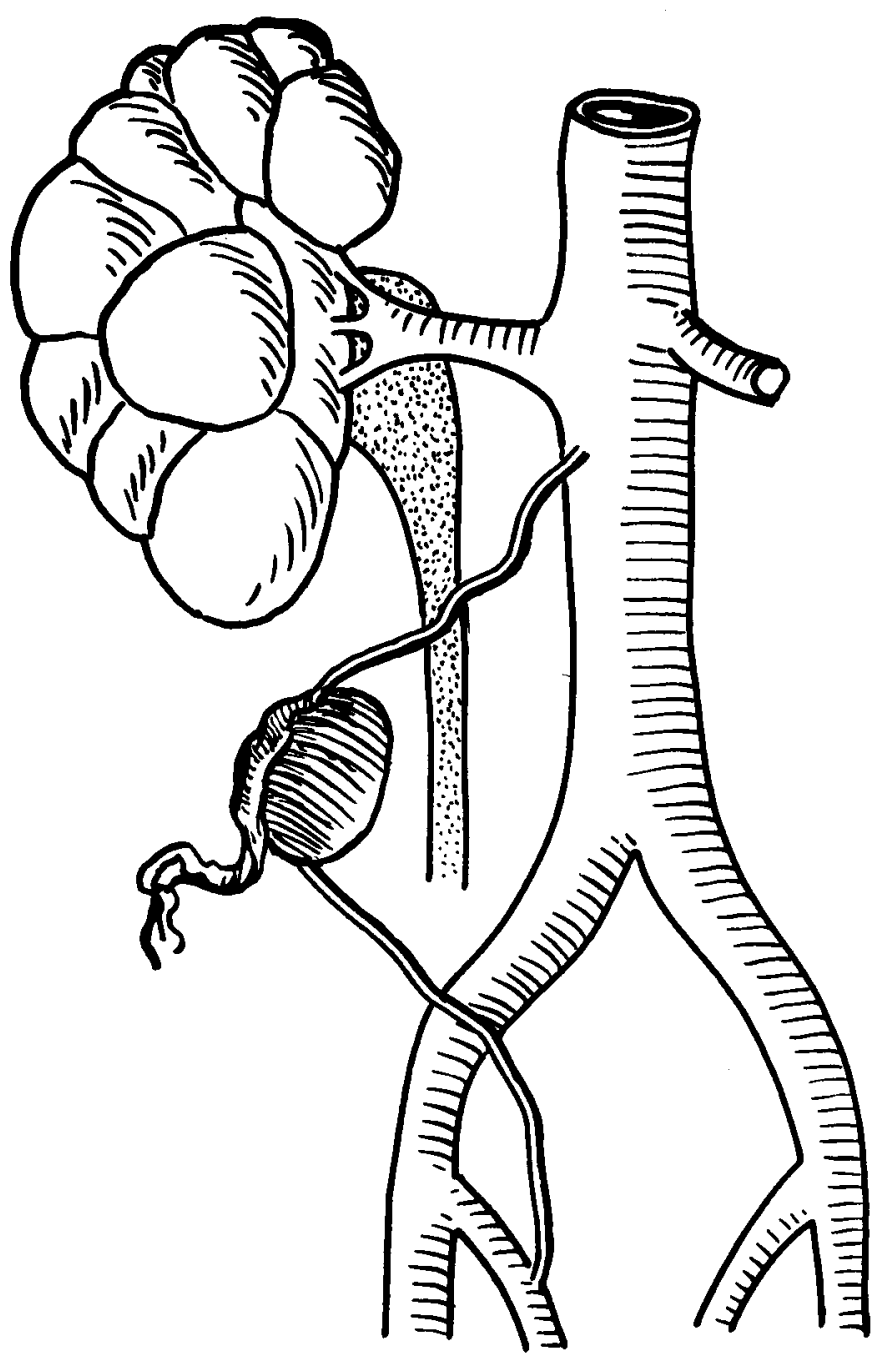

Fig. 2. Fetal testis irrigated by 1 artery from aorta (testicular) and 1 from internal iliac artery (deferential).

division of the testicular artery had a more reliable basis. Also, dissection around the vas deferens may result in injury to the deferential artery and, therefore, this area should be avoided if division of the testicular artery is being contemplated.

There have been some studies in adults and children of the vascularization of the testis and its importance for orchiopexy. However, to our knowledge there has been no study of the arterial supply of the testis during its migration in the fetal period. Of the testes we studied only $15.6 \%$ had migrated to the scrotum and they were all from fetuses 27 or more weeks after conception. These results on testicular migration are in agreement with our previous findings which showed that the testes are in the scrotum 26 weeks after conception. ${ }^{20}$

In $100 \%$ of the 32 fetuses studied we found at least 2 arteries irrigating the fetal testis. These vessels, the testicular and deferential arteries, constitute the main blood supply of the fetal testis and form the main anastomotic channels in the adult testis. ${ }^{15-17}$ We found 3 or 4 arteries supplying $76.6 \%$ of the testes, and the cremasteric artery in addition to the testicular and deferential arteries in $71.9 \%$ (fig. 1). Of the testes 2 testicular arteries originated from the aorta in 2 (fig. 3) and 2 deferential (vasal) arteries were present in 1 (fig. 3, $B$ ). The cremasteric artery reached the inferior pole of the testis in the area of the gubernacular attachment and, therefore, the gubernaculum should be kept 

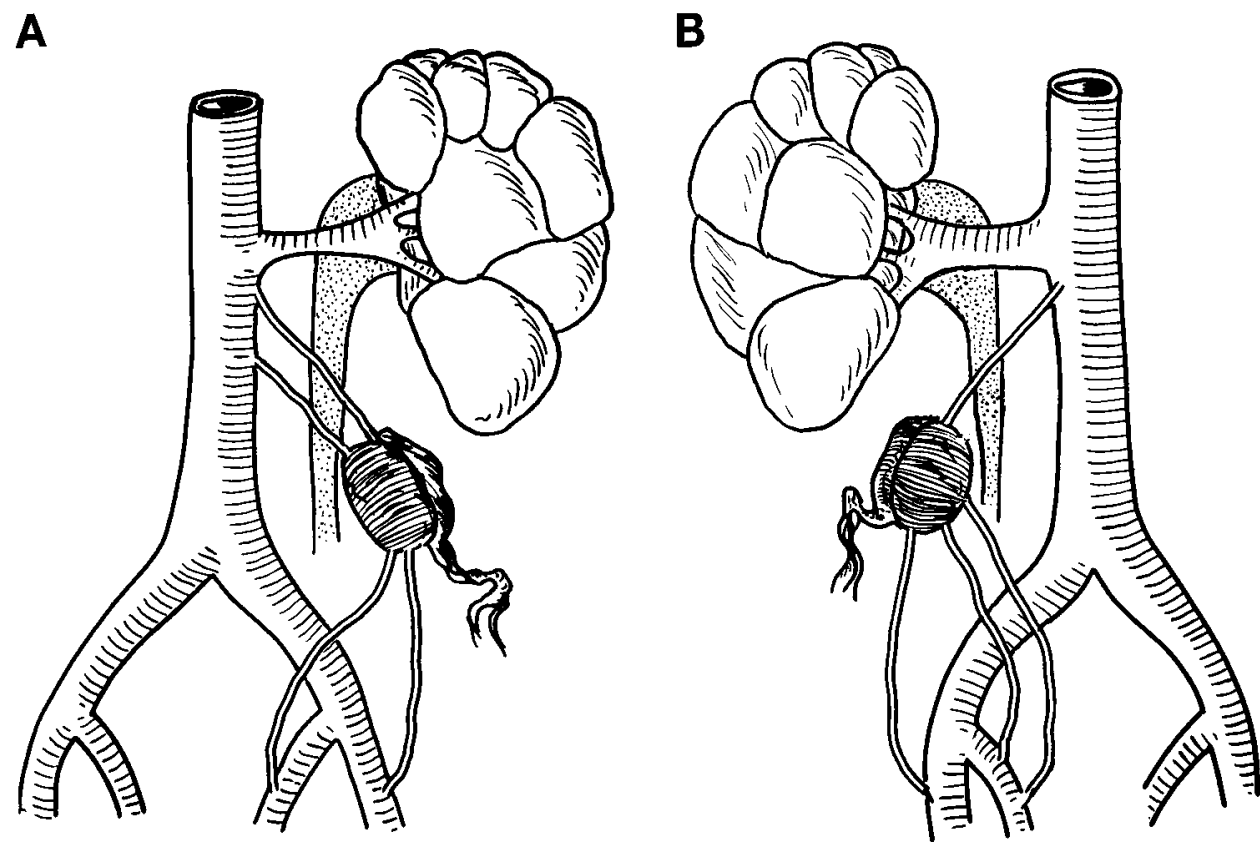

Fig. 3. $A$, fetal testis irrigated by 2 arteries from aorta (testicular), 1 from internal iliac artery (deferential) and 1 from external iliac artery (cremasteric). $B$, fetal testis irrigated by 1 artery from aorta (testicular), 2 from internal iliac artery (deferential) and 1 from external iliac artery (cremasteric).

intact during orchiopexy. Also, traction sutures, mainly in the inferior pole of the testis, should be avoided because the collateral circulation is at risk of severe damage. Fetal testes supplied by only 2 arteries were in the abdomen, which supports the idea that in the abdominal testis the collateral blood supply may be based mainly on the deferential artery, since the cremasteric collateral can only be significantly developed in the normally descended testis. ${ }^{13}$

Our findings show that the fetal testis, much like what occurs in the adult, has a multiple arterial supply. In all cases the testicular and deferential arteries were present. Since these vessels constitute the major blood supply to the testis, surgical procedures involving division of the testicular artery early in life have a sound anatomical basis.

Dr. Luiz Eduardo Macedo Cardoso reviewed our manuscript.

\section{REFERENCES}

1. Gill, B. and Kogan, S.: Cryptorchidism. Current concepts. Ped. Clin. N. Amer., 44: 1211, 1997.

2. Bloom, D. A.: Two-step orchiopexy with pelviscopic clip ligation of the spermatic vessels. J. Urol., 145: 1030, 1991.

3. Docimo, S. G.: The results of surgical therapy for cryptorchidism: a literature review and analysis. J. Urol., 154: 1148, 1995.

4. Elder, J. S.: Two-stage Fowler-Stephens orchiopexy in the management of intra-abdominal testes. J. Urol., 148: 1239, 1992.

5. Caldamone, A. A. and Amaral, J. F.: Laparoscopic stage 2 Fowler-Stephens orchiopexy. J. Urol., 152: 1253, 1994.

6. Gibbons, M. D., Cromie, W. J. and Duckett, J. W., Jr.: Management of the abdominal undescended testicle. J. Urol., 122: 76, 1979.

7. Fowler, R. and Stephens, F. D.: The role of testicular vascular anatomy in the salvage of high undescended testes. Aust. New Zeal. J. Surg., 29: 92, 1959.

8. Kogan, S. J., Houman, B. Z., Reda, E. F. and Levitt, B.: Orchiopexy of the high undescended testis by division of the sper- matic vessels: a critical review of 38 selected transactions. J. Urol., 141: 1416, 1989.

9. Koff, S. A. and Sethi, P. S.: Treatment of high undescended testes by low spermatic vessel ligation: an alternative to the Fowler-Stephens technique. J. Urol., part 2, 156: 799, 1996.

10. Jordan, G. H. and Winslow, B. H.: Laparoscopic single stage and staged orchiopexy. J. Urol., 152: 1249, 1994.

11. Esposito, C. and Garipoli, V.: The value of 2-step laparoscopic Fowler-Stephens orchiopexy for intra-abdominal testes. J. Urol., 158: 1952, 1997.

12. Silber, S. J.: The intra-abdominal testes: microvascular autotransplantation. J. Urol., 125: 329, 1981.

13. Bukowski, T. P., Wacksman, J., Billmire, D. A., Lewis, A. G. and Sheldon, C. A.: Testicular autotransplantation: a 17-year review of an effective approach to the management of the intraabdominal testis. J. Urol., 154: 558, 1995.

14. Wacksman, J., Billmire, D. A., Lewis, A. G. and Sheldon, C. A. Laparoscopically assisted testicular autotransplantation for management of the intrabdominal undescended testis. J. Urol., part 2, 156: 772, 1996.

15. Lee, L. M., Johnson, H. W. and McLoughlin, M. G.: Microdissection and radiographic studies of the arterial vasculature of the human testes. J. Ped. Surg., 19: 297, 1984.

16. Jarow, J. P.: Intratesticular arterial anatomy. J. Androl., 11: $255,1990$.

17. Jarow, J. P.: Clinical significance of intratesticular arterial anatomy. J. Urol., 145: 777, 1991.

18. Hern, W. N.: Correlation of fetal age and measurements between 10 and 26 weeks of gestation. Obst. Gynec., 63: 26, 1984.

19. Mecer, B. M., Sklar, S., Shariatmadar, A., Gillieson, M. S. and D'Alton, M. E.: Fetal foot length as a predictor of gestational age. Amer. J. Obst. Gynec., 156: 350, 1987.

20. Sampaio, F. J. B., Favorito, L. A.: Analysis of testicular migration during the fetal period in humans. J. Urol., 159: 540 , 1998.

21. Favorito, L. A., Sampaio, F. J.: Anatomical relationships between testis and epididymis during the fetal period (10-36 weeks postconception). Eur. Urol., 33: 121, 1998. 